\title{
A evolução do perfil da força de trabalho e das remunerações nos setores público e privado ao longo da década de 1990
}

Este artigo analisará a evolução do perfil da força de trabalho e dos salários praticados no setor público ao longo da década de 1990, comparando com a situação observada no setor privado, e apresentará algumas sugestões de medidas para a melhoria do sistema remuneratório. Para tal, inicialmente será realizada a comparação entre os perfis da força de trabalho nos dois setores, posteriormente entre as remunerações praticadas e, por fim, serão discutidas as distorções que permanecem na estrutura remuneratória e algumas alternativas para corrigi-las.

\section{$O$ perfil da força de trabalho ao longo da década de 1990}

A análise do perfil da força de trabalho que se seguirá foi elaborada com servidores dos três níveis de governo e trabalhadores do setor privado, destacando-se a diferença entre ambos. A fim de possibilitar a comparação entre os dois setores, foi adotada uma única fonte de dados: a Pesquisa Nacional por Amostra de Domicílios (PNAD), preparada pelo IBGE, em razão de sua abrangência geográfica e de seu questionário, além da reconhecida qualidade de sua metodologia. Inicialmente, este diagnóstico mostrará a evolução do emprego e as características da força de trabalho, por meio da análise dos dados referentes a três anos da década considerada (1993, 1996 e 1999), visando possibilitar, além das análises entre os setores, o estudo da evolução temporal das variáveis analisadas.

$\mathrm{O}$ trabalho não se estendeu a décadas passadas para as quais existem PNADs disponíveis, porque as pesquisas anteriores seguiam uma
Nelson Marconi é doutor em Economia pela Fundação Getúlio Vargas/ SP, professor doutor de Economia da Pontifícia Universidade Católica/SP e ex-diretor de Carreiras e Remuneração do Ministério da Administração Federal e Reforma do Estado.

Contato: nmarconi@ uol.com.br 
metodologia diversa e seria necessário caracterizar um trabalhador como servidor público a partir da definição de algumas hipóteses, uma vez que, essa questão não integrando o questionário da PNAD antes de 1992, isso podia resultar em comparações viesadas entre os resultados obtidos a partir das pesquisas anteriores e os das posteriores a essa data. De toda forma, a inclusão desses três anos na análise permite avaliar o comportamento desses mercados de trabalho ao longo da década de 1990. A pesquisa também não inclui dados mais recentes, porque, até o momento da elaboração deste trabalho, os microdados referentes à PNAD de 2001 ainda não haviam sido divulgados ${ }^{2}$.

O universo considerado nos cálculos apresentados inclui as pessoas empregadas, exceto os que trabalham por conta própria, os trabalhadores domésticos e os empregadores, com idade entre 18 e 65 anos, das áreas urbanas do país, para possibilitar a aproximação entre algumas características dos mercados de trabalho público e privado ${ }^{3}$. Foram desconsideradas as informações que não explicitavam se o trabalhador atuava no setor público ou privado e consideradas apenas as relativas ao trabalho principal da pessoa, uma vez que a ocupação secundária possui características específicas e, se incluída, poderia distorcer os resultados. As amostras resultantes contêm para cada ano cerca de 60.000 indivíduos. Para possibilitar a comparação entre os salários individuais, estes valores foram ajustados por meio da sua divisão pelo número de horas trabalhadas na semana e posterior multiplicação por 44. Com isso, calcula-se o valor de todos os salários para uma jornada semanal uniforme de 44 horas ${ }^{4}$.

Os dados foram segmentados inicialmente entre o setor privado e o público em geral e posteriormente, neste último grupo, entre os três níveis de governo e, em algumas análises, também entre estatutários, militares e celetistas. Essa divisão justifica-se porque, enquanto o salário dos estatutários e militares é definido pela legislação e, teoricamente, de forma unilateral, os salários dos celetistas resultam de negociações e podem ser definidos por arbitragem, o que implica processos de fixação das remunerações relativamente distintos. Adicionalmente, o comportamento dos salários e do emprego deste segmento foi bem distinto do observado para os estatutários ao longo da década, como veremos a seguir, assim como o perfil das ocupações destes dois grupos é distinto na esfera federal, enquanto nos níveis estadual e municipal é mais semelhante. Não foi incluído o fracionamento entre trabalhadores com ou sem carteira, pois no setor público esta última situação inclui grande parte dos servidores - os estatutários, por exemplo, não possuem carteira assinada -, o que não possibilitaria caracterização específica das condições de trabalho baseada no registro em carteira, como a observada no setor privado. 
Tabela 1: Nível de emprego por setor e regime de trabalho - empregados entre 18 e 65 anos

\begin{tabular}{c|r|r|r|r|r|r}
\hline & \multicolumn{2}{|c}{ Número de empregados } & \multicolumn{1}{c}{ Índice $(\mathbf{1 9 9 3}=\mathbf{1 0 0})$} \\
\hline & \multicolumn{1}{c|}{1993} & 1996 & \multicolumn{1}{c}{1999} & 1993 & 1996 & 1999 \\
\hline Privado & 18.613 .498 & 20.227 .471 & 21.173 .920 & 100 & 109 & 114 \\
\hline Público & 6.930 .173 & 6.925 .067 & 6.853 .368 & 100 & 100 & 99 \\
\hline Federal & 1.392 .746 & 1.373 .130 & 1.224 .993 & 100 & 99 & 88 \\
\hline Estatutário & & & & & & \\
+ militar & 845.582 & 877.743 & 801.382 & 100 & 104 & 95 \\
\hline Estatutário & 603.058 & 602.312 & 525.522 & 100 & 100 & 87 \\
\hline Militar & 242.524 & 275.431 & 275.860 & 100 & 114 & 114 \\
\hline Celetista & 547.164 & 495.387 & 423.611 & 100 & 91 & 77 \\
\hline Estadual & 3.245 .108 & 3.102 .412 & 2.898 .286 & 100 & 96 & 89 \\
\hline Estatutário & 2.068 .083 & 2.156 .377 & 2.105 .169 & 100 & 104 & 102 \\
\hline Celetista & 1.177 .025 & 946.035 & 793.117 & 100 & 80 & 67 \\
\hline Municipal & 2.292 .319 & 2.449 .525 & 2.730 .089 & 100 & 107 & 119 \\
\hline Estatutário & 930.146 & 1.187 .089 & 1.418 .613 & 100 & 128 & 153 \\
\hline Celetista & 1.361 .854 & 1.262 .436 & 1.311 .476 & 100 & 93 & 96 \\
\hline Total estatutário & 3.601 .287 & 3.945 .778 & 4.049 .304 & 100 & 110 & 112 \\
\hline Total celetista & 3.086 .043 & 2.703 .858 & 2.528 .204 & 100 & 88 & 82 \\
\hline Total geral & 25.543 .671 & 27.152 .538 & 28.027 .288 & 100 & 106 & 110 \\
\hline
\end{tabular}

Os dados das tabelas 1 e 2 indicam que o total de empregos públicos manteve-se praticamente estável ao longo da década, enquanto a sua participação no emprego total sofreu ligeira queda, indicando que aproximadamente $1 / 4$ do universo dos trabalhadores considerados - somente empregados entre 18 e 65 anos - encontra-se no setor público.

Quando se avalia a composição do emprego público, porém, observase que a evolução não foi uniforme. Embora no geral essa resolução tenha permanecido relativamente estável, observam-se crescimento acentuado nos municípios e redução nas esferas federal e estadual, principalmente entre os celetistas. É bastante provável que tal comportamento tenha sido fruto do processo de privatizações, uma vez que nas estatais e empresas públicas não existem servidores estatutários. 
Tabela 2: Nível de emprego por setor e regime de trabalho. Participação no total de empregados entre 18 e 65 anos (em\%)

\begin{tabular}{l|r|r|r}
\hline & $\mathbf{1 9 9 3}$ & $\mathbf{1 9 9 6}$ & $\mathbf{1 9 9 9}$ \\
\hline Privado & 72,9 & 74,5 & 75,5 \\
\hline Público & 27,1 & 25,5 & 24,5 \\
\hline Federal & 5,5 & 5,1 & 4,4 \\
\hline $\begin{array}{l}\text { Estatutário } \\
+ \text { militar }\end{array}$ & 3,3 & 3,2 & 2,9 \\
\hline Estatutário & 2,4 & 2,2 & 1,9 \\
\hline Militar & 0,9 & 1,0 & 1,0 \\
\hline Celetista & 2,1 & 1,8 & 1,5 \\
\hline Estadual & 12,7 & 11,4 & 10,3 \\
\hline Estatutário & 8,1 & 7,9 & 7,5 \\
\hline Celetista & 4,6 & 3,5 & 2,8 \\
\hline Municipal & 9,0 & 9,0 & 9,7 \\
\hline Estatutário & 3,6 & 4,4 & 5,1 \\
\hline Celetista & 5,3 & 4,6 & 4,7 \\
\hline Total estatutário & 14,1 & 14,5 & 14,4 \\
\hline Total celetista & 12,1 & 10,0 & 9,0 \\
\hline Total militar & 0,9 & 1,0 & 1,0 \\
\hline Total geral & 100,0 & 100,0 & 100,0 \\
\hline
\end{tabular}

Os dados da tabela 3, por sua vez, indicam que os estados da Região Norte que correspondem aos ex-territórios são aqueles que apresentam participação maior do emprego público na composição de sua força de trabalho, seja porque herdaram estrutura administrativa superdimensionada no setor público, oriunda da época em que não possuíam autonomia e sofriam forte intervenção do governo federal, seja porque a atividade privada ainda é incipiente nesta região.

Alguns estados da Região Nordeste, que podem ser incluídos no grupo que apresenta as menores rendas per capita do país e, portanto, podem ser considerados os mais pobres, também apresentam participação relevante do emprego público na força de trabalho, constituída sobre o critério considerado e já explicado, isto é, empregados entre 18 e 65 anos. Nesse caso, uma das prováveis explicações para esse comportamento reside na necessidade de geração de empregos em região cuja atividade econômica é bastante debilitada (vide sua renda per capita) ${ }^{5}$.

A capital do país, por sua vez, ao contrário do que estabelece o senso comum, não possui participação majoritária de servidores em sua força de trabalho, sendo menor que a dos casos anteriormente analisados. É bastante provável que o desenvolvimento do Distrito Federal em torno 
da estrutura do governo federal que abriga esteja propiciando a consolidação do setor privado na região.

Tabela 3: Participação do emprego público no total de empregos, considerando os empregados entre 18 e 65 anos (em \%)

\begin{tabular}{|c|c|c|c|}
\hline & 1993 & 1996 & 1999 \\
\hline Rondônia & 39 & 39 & 42 \\
\hline Acre & 64 & 57 & 60 \\
\hline Amazonas & 37 & 36 & 38 \\
\hline Roraima & 59 & 55 & 67 \\
\hline Pará & 37 & 34 & 33 \\
\hline Amapá & 45 & 56 & 59 \\
\hline Tocantins & 53 & 48 & 47 \\
\hline Maranhão & 42 & 43 & 46 \\
\hline Piauí & 46 & 45 & 39 \\
\hline Ceará & 32 & 29 & 26 \\
\hline Rio Grande do Norte & 48 & 40 & 38 \\
\hline Paraíba & 55 & 43 & 46 \\
\hline Pernambuco & 31 & 29 & 29 \\
\hline Alagoas & 50 & 50 & 42 \\
\hline Sergipe & 42 & 39 & 36 \\
\hline Bahia & 34 & 33 & 29 \\
\hline Minas Gerais & 27 & 24 & 23 \\
\hline Espírito Santo & 30 & 27 & 26 \\
\hline Rio de Janeiro & 23 & 24 & 23 \\
\hline São Paulo & 19 & 17 & 17 \\
\hline Paraná & 23 & 25 & 22 \\
\hline Santa Catarina & 21 & 21 & 19 \\
\hline Rio Grande do Sul & 25 & 24 & 23 \\
\hline Mato Grosso do Sul & 36 & 34 & 33 \\
\hline Mato Grosso & 35 & 31 & 28 \\
\hline Goiás & 33 & 27 & 27 \\
\hline Distrito Federal & 47 & 45 & 39 \\
\hline Total & 27 & 26 & 24 \\
\hline
\end{tabular}

Se observarmos a distribuição dos servidores e dos trabalhadores do setor privado de acordo com as ocupações exercidas, nota-se que há disparidade considerável entre as atividades observadas com maior frequiência em cada um dos setores aos quais estes grupos pertencem. 
O Anexo apresenta tabelas que mostram tais ocupações para os funcionários públicos federais (estatutários e celetistas), estaduais e municipais e trabalhadores do setor privado. A distinção entre os resultados apurados para os dois grupos deve-se à diferença entre os objetivos de seus respectivos setores e às atividades que predominam em cada um deles. Assim, enquanto no setor público existe grande número de pessoas cuja atuação é direcionada ao ensino, à saúde, ao policiamento e à fiscalização, no setor privado há grande número de comerciantes e pessoas que desempenham atividades operacionais vinculadas ao setor produtivo ou à área de alimentação.

É evidente também a diferença entre a qualidade dos postos de trabalho nos dois setores. Entre as ocupações mais frequientes no setor privado, três delas correspondem a posições de chefia e as demais (28) não requerem formação de nível superior para o seu desempenho, o que denota a predominância de postos operacionais entre os existentes neste setor, além de demandarem nível de qualificação menor dos integrantes desse segmento do mercado de trabalho, conforme será discutido a seguir. Já no setor público, ainda que as ocupações prevalecentes sejam as da área administrativa, existem diversas entre o grupo das observadas com maior frequiência que requerem escolaridade de nível superior.

Assim, ainda que seja recorrente a crítica de que a composição da força de trabalho está desequilibrada no setor público, pois existiria um grande número de servidores desempenhando atividades na área de suporte, a qualidade dos postos é, em média, superior à observada no setor privado, pois a participação relativa de atividades das áreas operacionais naquele é bem inferior à observada neste setor.

Esse resultado também comprova as disparidades existentes no mercado de trabalho privado no país: áreas de elevada concentração de tecnologia, numericamente minoritárias (a ponto de não constituírem grupo identificável na amostra analisada), coexistem com uma grande maioria de ocupações precárias ou que exigem menor qualificação de seus ocupantes. Tal perfil pode ser reflexo do grau de desenvolvimento do país ou do nível educacional da população e contribui fortemente para a definição dos níveis salariais observados no setor privado da economia brasileira.

O perfil de ocupações no setor público, por sua vez, modifica-se dependendo do nível de governo analisado. No governo federal, há uma distinção entre o perfil observado para os funcionários estatutários e celetistas, conforme pode se depreender das tabelas anexas. Os objetivos das organizações da administração direta, autarquias e fundações (quais sejam, de forma bem resumida, formulação e execução de políticas públicas) são diferentes dos definidos para as empresas públicas (produção de bens e serviços) e, com isso, as atividades desempenhadas por seus funcionários, nas respectivas áreas finalísticas, também o serão. Como no primeiro grupo 
de organizações predominam os estatutários e, no segundo, os celetistas, os cargos existentes em cada um deles também serão diferentes.

As ocupações da área administrativa e de suporte são predominantes no grupo dos servidores federais estatutários. Somente os assistentes administrativos, ajudantes/auxiliares, secretárias e datilógrafos constituíam 22,2\% da força de trabalho entre 18 e 65 anos em 1999. Vigias, porteiros, motoristas e faxineiros, outros 5,4\%. Em contrapartida, os profissionais das atividades finalísticas das áreas de educação e saúde são 16,6\%; fiscais de tributo são $2,4 \%$ e policiais federais correspondem a 2,1\%. Em relação aos federais celetistas, comportamento semelhante pode ser observado ${ }^{6}$.

É claro o excesso de pessoas desempenhando atividades de suporte; se as demais ocupações observadas forem também contabilizadas, esse comportamento se mantém, conforme pode ser observado no Anexo. Assim, enquanto no setor privado sobressaem as ocupações de caráter mais operacional, mas provavelmente associadas às atividades finalísticas de seus setores, no setor público federal prevalecem ocupações mais complexas, porém essencialmente vinculadas às áreas meio das organizações.

Já, em relação aos servidores públicos estaduais, nota-se que predominam os profissionais vinculados à educação, que constituíam $24,9 \%$ do total em 1999. Os policiais e bombeiros constituem $14 \%$ da força de trabalho no levantamento realizado, enquanto os profissionais da área de saúde, $5,3 \%$. Em relação às atividades das áreas meio, os assistentes administrativos, ajudantes/auxiliares e secretárias correspondem a 10,8\% e os vigias, faxineiros e motoristas, a $7,1 \%$ do total. O perfil parece mais adequado que o das ocupações exercidas pelos servidores federais; há concentração de funcionários nas principais atividades que os governos estaduais devem realizar (educação, policiamento e saúde); a participação relativa desse grupo é superior à observada para os que desempenham atividades de suporte.

Na esfera municipal, também prevalecem os profissionais das áreas de educação $(21,8 \%)$ e saúde $(8,7 \%)$. Os assistentes administrativos, ajudantes/auxiliares e secretárias correspondem a 10,2\% do total. Há, entretanto, grande concentração de ocupações nas áreas operacionais, algumas de suporte (vigias, faxineiros e motoristas, 15,9\%) e outras nas áreas finalísticas (lixeiros, cozinheiros e pedreiros, $8,1 \%$ do total), que correspondem a atividades mais simples, fato que torna o perfil das categorias ocupacionais no serviço público municipal mais próximo daquele que predomina na esfera privada. Essa constatação pode refletir maior proximidade entre o mercado de trabalho do serviço municipal e o privado - dado que o primeiro deve ser fortemente influenciado pelas características econômicas e sociais locais, a exemplo do segundo - ou caracterizar uma política de oferta de postos de trabalho para pessoas menos qualificadas nos serviços municipais, a fim de atenuar os impactos do desemprego. 
Os dados permitem afirmar que a composição das ocupações melhorou nas três esferas de governo, ao longo da década de 1990; a participação de professores, policiais e profissionais da área de saúde aumentou no período, nas esferas do serviço público estadual e municipal, refletindo inclusive a descentralização da execução de serviços do nível federal para os demais níveis de governo.

Por exemplo, houve crescimento proporcionalmente maior de professores de primeiro grau e de profissionais da área de saúde nos municípios, para os quais foram descentralizados esses serviços, e crescimento maior de professores de segundo grau nos estados, os quais tradicionalmente se ocupam da oferta dos cursos desse nível.

No governo federal, por sua vez, é mais difícil identificar tendência clara em relação aos estatutários, foco da análise neste segmento, pois as alterações no perfil não foram significativas, mas é possível notar que houve crescimento da participação na força de trabalho, ainda que tímido, da maior parte das ocupações vinculadas às áreas finalísticas.

A análise permite afirmar que houve direcionamento da composição da força de trabalho para o desenvolvimento das atividades típicas de Estado nos três níveis de governo, o que é salutar. É nítida a tendência de maior correlação entre as ocupações observadas e a distribuição de funções entre as esferas de governo. 
Tabela 4: Distribuição dos trabalhadores

por anos de estudo (em \%)

0 a 4 anos de estudo

\begin{tabular}{l|c|c|c}
\hline & $\mathbf{1 9 9 3}$ & $\mathbf{1 9 9 6}$ & $\mathbf{1 9 9 9}$ \\
\hline Serv. federais estatutários & 11 & 7 & 5 \\
\hline Serv. federais celetistas & 9 & 8 & 12 \\
\hline Serv. federais militares & 5 & 3 & 2 \\
\hline Serv. estaduais & 14 & 12 & 9 \\
\hline Serv. municipais & 38 & 31 & 27 \\
\hline Trab. setor privado & 36 & 31 & 26 \\
\hline
\end{tabular}

5 a 8 anos de estudo

\begin{tabular}{l|c|c|c}
\hline & $\mathbf{1 9 9 3}$ & $\mathbf{1 9 9 6}$ & $\mathbf{1 9 9 9}$ \\
\hline Serv. federais estatutários & 11 & 10 & 8 \\
\hline Serv. federais celetistas & 11 & 10 & 7 \\
\hline Serv. federais militares & 27 & 26 & 21 \\
\hline Serv. estaduais & 14 & 13 & 12 \\
\hline Serv. municipais & 17 & 20 & 17 \\
\hline Trab. setor privado & 30 & 32 & 30 \\
\hline
\end{tabular}

9 a 11 anos de estudo

\begin{tabular}{l|c|c|c}
\hline & $\mathbf{1 9 9 3}$ & $\mathbf{1 9 9 6}$ & $\mathbf{1 9 9 9}$ \\
\hline Serv. federais estatutários & 30 & 33 & 32 \\
\hline Serv. federais celetistas & 36 & 39 & 34 \\
\hline Serv. federais militares & 49 & 50 & 58 \\
\hline Serv. estaduais & 37 & 38 & 39 \\
\hline Serv. municipais & 27 & 31 & 36 \\
\hline Trab. setor privado & 25 & 28 & 33 \\
\hline
\end{tabular}

12 ou mais anos de estudo

\begin{tabular}{l|c|c|c}
\hline & $\mathbf{1 9 9 3}$ & $\mathbf{1 9 9 6}$ & $\mathbf{1 9 9 9}$ \\
\hline Serv. federais estatutários & 50 & 50 & 55 \\
\hline Serv. federais celetistas & 45 & 44 & 47 \\
\hline Serv. federais militares & 19 & 20 & 20 \\
\hline Serv. estaduais & 35 & 38 & 40 \\
\hline Serv. municipais & 17 & 18 & 21 \\
\hline Trab. setor privado & 9 & 9 & 11 \\
\hline
\end{tabular}

Fonte: PNAD/IBGE.

Inclui os trabalhadores entre 18 e 65 anos. 
A análise do nível de escolaridade mostra forte diferenciação entre os grupos selecionados, fato que contribui para explicar as diferentes composições da força de trabalho no tocante às ocupações.

Inicialmente deve-se atentar para a evolução do nível de escolaridade de todos os segmentos observados ao longo da década. Com exceção dos servidores celetistas, a participação relativa das pessoas com quatro ou menos anos de estudo reduziu no período, enquanto cresceu a dos trabalhadores com 12 ou mais anos de estudo, à exceção do grupo dos militares, o qual apresenta relativa estabilidade neste segmento.

Para os trabalhadores do setor privado e os servidores municipais, crescimento proporcionalmente maior foi observado no grupo das pessoas que possuem entre 9 e 11 anos de estudo; para os servidores estaduais e federais estatutários, no grupo de funcionários que possuem 12 ou mais anos de estudo.

Os dados mostram que a evolução do nível educacional foi satisfatória para a totalidade dos integrantes do mercado de trabalho que são empregados e possuem entre 18 e 65 anos. No caso específico dos servidores estaduais e federais estatutários, foram registrados inclusive avanços substanciais na proporção de pessoas que possuem escolaridade mais elevada.

A distribuição dos trabalhadores de acordo com os diferentes níveis de escolaridade exibe, no setor privado, perfil inferior menos satisfatório que o verificado nos diversos segmentos do setor público. Essa distribuição vai ao encontro do perfil das ocupações observadas com maior freqüência no setor privado, representando forte indício de que a possibilidade de melhoria das condições da oferta de trabalho neste setor está correlacionada ao aumento dos anos de estudo dos trabalhadores que nele atuam.

O melhor perfil é o dos servidores federais estatutários, que evoluiu bastante ao longo da década. A distribuição percentual dos anos de estudo dos servidores municipais, por sua vez, é a que mais se aproxima da observada no setor privado, fato que novamente suscita a possibilidade de os mercados de trabalho privado e público municipal apresentarem características contíguas.

A idade média dos servidores públicos é mais elevada que a dos trabalhadores do setor privado. Em relação ao número médio de anos de serviço na atual ocupação, o comportamento é o mesmo, com destaque em ambas situações para os servidores federais estatutários e estaduais. A combinação desses indicadores aponta que os servidores possuíam mais experiência que os trabalhadores do setor privado no desempenho de suas respectivas atividades no momento da pesquisa e, por consequiência, maior acúmulo de capital humano específico relativo a uma determinada habilidade, isto é, maior conhecimento dos processos de trabalho que devem 
realizar. Adicionalmente, o resultado desses indicadores também permite inferir que a rotatividade é menor no setor público, conforme esperado.

A análise demonstra, no tocante ao número de anos de serviço, que novamente o perfil dos servidores municipais é o que mais se aproxima do observado para os trabalhadores do setor privado.

Tabela 5: Idade média dos trabalhadores

\begin{tabular}{l|c|c|c}
\hline & $\mathbf{1 9 9 3}$ & $\mathbf{1 9 9 6}$ & $\mathbf{1 9 9 9}$ \\
\hline Serv. federais estatutários & 40 & 40 & 41 \\
\hline Serv. federais celetistas & 36 & 35 & 36 \\
\hline Serv. federais militares & 28 & 28 & 28 \\
\hline Serv. estaduais & 37 & 38 & 39 \\
\hline Serv. municipais & 37 & 37 & 38 \\
\hline Trab. setor privado & 32 & 32 & 33 \\
\hline
\end{tabular}

Tabela 6: Número médio de anos de serviço no emprego atual

\begin{tabular}{l|c|c|c}
\hline & $\mathbf{1 9 9 3}$ & $\mathbf{1 9 9 6}$ & $\mathbf{1 9 9 9}$ \\
\hline Serv. federais estatutários & 13 & 12 & 13 \\
\hline Serv. federais celetistas & 10 & 9 & 9 \\
\hline Serv. federais militares & 9 & 9 & 8 \\
\hline Serv. estaduais & 10 & 11 & 11 \\
\hline Serv. municipais & 7 & 7 & 8 \\
\hline Trab. setor privado & 4 & 4 & 4 \\
\hline
\end{tabular}

Fonte: PNA/IBGE.

Inclui os trabalhadores entre 18 e 65 anos.

Resumindo, o perfil dos servidores públicos é qualitativamente melhor que o observado nos trabalhadores do setor privado. Enquanto neste setor predominam atividades operacionais ou pouco complexas, no setor público observam-se, com maior frequiência, ocupações associadas à realização das atividades típicas de Estado e de suporte ${ }^{7}$, além de o nível de escolaridade e a experiência serem maiores. As características dos integrantes do mercado de trabalho dos servidores públicos municipais são as que mais se aproximam das observadas no setor privado.

As distinções entre as características dos empregados dos mercados de trabalho público e privado vão explicar parte das disparidades entre os salários dos dois setores. Essa questão será discutida na próxima seção. 
Os diferenciais de salário entre os setores público/privado no período considerado

Os dados referentes à evolução do salário real médio (tabela 7) mostram que, com exceção dos celetistas - basicamente os federais e estaduais -, o salário das demais categorias de servidores incluídas na tabela apresentou crescimento maior que o registrado para os trabalhadores do setor privado entre 1993 e 1999.

Tabela 7: Salário real médio (valores de set/99 - deflator: INPC)

\begin{tabular}{l|r|r|r|r|r|r}
\hline \multicolumn{4}{c}{ Valores } & \multicolumn{3}{c}{ Índices (1993 =100) } \\
\hline & $\mathbf{1 9 9 3}$ & $\mathbf{1 9 9 6}$ & $\mathbf{1 9 9 9}$ & $\mathbf{1 9 9 3}$ & $\mathbf{1 9 9 6}$ & $\mathbf{1 9 9 9}$ \\
\hline Privado & 454 & 562 & 527 & 100 & 124 & 116 \\
\hline Público & 816 & 1.001 & 990 & 100 & 123 & 121 \\
\hline Federal & 1.440 & 1.512 & 1.598 & 100 & 105 & 111 \\
\hline Estatutário + Militar & 1.304 & 1.565 & 1.705 & 100 & 120 & 131 \\
\hline Estatutário & 1.511 & 1.764 & 2.014 & 100 & 117 & 133 \\
\hline Militar & 762 & 1.080 & 1.069 & 100 & 142 & 140 \\
\hline Celetista & 1.656 & 1.412 & 1.400 & 100 & 85 & 85 \\
\hline Estadual & 783 & 1.029 & 1.038 & 100 & 131 & 132 \\
\hline Estatutário & 777 & 1.041 & 1.082 & 100 & 134 & 139 \\
\hline Celetista & 795 & 1.001 & 925 & 100 & 126 & 116 \\
\hline Municipal & 395 & 607 & 598 & 100 & 154 & 151 \\
\hline Estatutário & 480 & 690 & 661 & 100 & 144 & 138 \\
\hline Celetista & 333 & 527 & 528 & 100 & 158 & 158 \\
\hline Total estatutário & 846 & 1.074 & 1.083 & 100 & 127 & 128 \\
\hline Total celetista & 785 & 880 & 829 & 100 & 112 & 106 \\
\hline Total militar & 762 & 1.080 & 1.069 & 100 & 142 & 140 \\
\hline & & & & & &
\end{tabular}

A tabela 8 demonstra os diferenciais brutos (sem controles para características demográficas e produtivas) de salário médio entre o setor público (e os segmentos aqui considerados) e o privado. Ao longo da década, todas as categorias de servidores incluídas na tabela passaram a receber salários iguais ou superiores, tendo o diferencial se elevado, exceto para os celetistas, o que reflete a evolução distinta dos salários nos setores público e privado no período ${ }^{8}$. 
Tabela 8: Diferencial salarial bruto entre os setores público/privado (em \% sobre o salário médio do setor privado)

\begin{tabular}{l|c|c|c}
\hline & $\mathbf{1 9 9 3}$ & $\mathbf{1 9 9 6}$ & $\mathbf{1 9 9 9}$ \\
\hline Privado & - & - & - \\
\hline Público & 80 & 78 & 88 \\
\hline Federal & 217 & 169 & 203 \\
\hline Estatutário + Militar & 187 & 178 & 223 \\
\hline Estatutário & 233 & 214 & 282 \\
\hline Militar & 68 & 92 & 103 \\
\hline Celetista & 264 & 151 & 166 \\
\hline Estadual & 72 & 83 & 97 \\
\hline Estatutário & 71 & 85 & 105 \\
\hline Celetista & 75 & 78 & 75 \\
\hline Municipal & -13 & 8 & 13 \\
\hline Estatutário & 6 & 23 & 25 \\
\hline Celetista & -27 & -6 & 0 \\
\hline Total estatutário & 86 & 91 & 105 \\
\hline Total celetista & 73 & 56 & 57 \\
\hline Total militar & 68 & 92 & 103 \\
\hline
\end{tabular}

Os dados até aqui apresentados mostram que, em cenário de crise fiscal como o vivenciado ao longo da década de 1990, que persiste até o presente, os governantes parecem ter optado pela melhoria do salário médio acima do crescimento observado no mercado privado e abdicaram de aumento do emprego público, que, em termos agregados, permaneceu praticamente estável ao longo da década. $\mathrm{O}$ ajuste recaiu de forma mais intensa, na verdade, sobre os servidores celetistas, ainda que o diferencial salarial para este grupo permaneça positivo, o que possivelmente é explicado pelo processo de privatizações ${ }^{9}$. Como resultado de todo esse cenário, o diferencial bruto de salários entre o setor público e o privado aumentou entre 1993 e 1999.

O cálculo do diferencial bruto não considera qualquer tipo de controle em relação às características pessoais que vão influir no diferencial de salários, ou no salário relativo dos indivíduos. Na verdade, uma parcela do diferencial bruto deve ser explicado pelas diferenças em características demográficas e produtivas das pessoas que integram os setores público e privado. Por exemplo, a partir da análise efetuada na seção anterior, seria possível afirmar que os servidores recebem melhores salários, porque seu perfil é mais qualificado. Assim, é necessário comparar o salário para trabalhadores com características idênticas, cada qual trabalhando em um dos setores. Se, nesse caso, os salários forem distintos, fica configurada a 
segmentação entre os dois mercados de trabalho. Esse é o teste que se realizará nesta seção.

No Brasil, o primeiro autor a tratar da questão foi Macedo (1985). Outros textos relevantes sobre o assunto são os de Urani e Ramalho (1995), Gill et al. (1997) e Barros et al. (1997) ${ }^{10}$.

O modelo mais geral de determinação da estrutura de salários aqui adotado define que a remuneração de determinado trabalhador vai depender de suas características pessoais (demográficas e produtivas) e de uma série de variáveis, que alterarão o nível de salário definido para tais características, ou que poderão modificar o retorno que os trabalhadores recebem em virtude de possuí-las ${ }^{11}$.

As características pessoais seriam divididas em dois subgrupos: as demográficas e as produtivas. Entre as demográficas estariam incluídos o gênero, a cor e a idade. Essas características - com ênfase para as duas primeiras, apesar de que a terceira pode sofrer do mesmo problema - podem ser alvo de discriminação e implicar o recebimento de diferentes remunerações, mesmo que a sua produtividade ou as características produtivas sejam semelhantes.

As características produtivas corresponderiam àquelas que influiriam de forma direta na capacidade e nas habilidades adquiridas para o trabalho e, conseqüentemente, na própria produtividade dos empregados. Nesse grupo estariam incluídos o nível educacional da pessoa, a experiência no trabalho e, de certa forma, a idade, que também pode captar algum efeito de alterações na capacidade produtiva, se a pessoa investir continuamente em capacitação, bem como permanecer empregada ao longo do tempo e, com isso, aumentar sua experiência no trabalho ${ }^{12}$.

O outro grupo de variáveis que contribuirá para determinar os salários - alterando o patamar resultante do conjunto de suas características pessoais - será constituído pelas variáveis que mensuram o grau de sindicalização e a localização geográfica dos trabalhadores.

A localização geográfica do trabalhador será uma variável que tentará captar o poder explicativo de alguns aspectos não pecuniários sobre a formação de salários, como as condições de vida das diversas cidades, e das diferenças regionais entre as estruturas de mercado de trabalho. Por seu turno, o poder de barganha dos trabalhadores, representado pelo grau de adesão aos sindicatos ${ }^{13}$, pode gerar, caso o empregado esteja associado a uma entidade sindical e venha a se beneficiar de suas negociações, um prêmio calculado sobre o salário que resultaria das características pessoais observadas para este mesmo trabalhador.

Portanto, o salário de um indivíduo seria equivalente a:

$\mathrm{W}_{\mathrm{i}}=\mathrm{W}_{\text {ic }} *\left(1+\mathrm{R}_{\mathrm{i}}\right)$,

$\mathrm{W}_{\text {ic }}=\mathrm{f}$ (gênero, cor, idade, escolaridade, experiência no trabalho),

$\mathrm{R}_{\mathrm{i}}=\mathrm{f}$ (localização geográfica e poder de barganha dos trabalhadores), 
onde:

$\mathrm{W}_{\mathrm{i}}=$ salário do indivíduo $\mathrm{i}$,

$\mathrm{W}_{\text {ic }}=$ parcela do salário do indivíduo i, que depende de suas características demográficas e produtivas,

$\mathrm{R}_{\mathrm{i}}=$ demais variáveis que modificarão o valor de $\mathrm{W}_{\mathrm{ic}}$; a interação desse conjunto de variáveis determinará um valor para $\mathrm{R}_{\mathrm{i}}$, que fará $\mathrm{W}_{\mathrm{i}}$ oscilar em torno de $\mathrm{W}_{\text {ic }}$, portanto $\mathrm{R}_{\mathrm{i}}$ pode ser considerado prêmio ou renda econômica em relação ao salário determinado pelas características pessoais.

Logo, a primeira equação utilizada para os testes incluirá as seguintes variáveis explicativas: idade (como uma das proxies para a experiência ou para o capital humano específico), idade ao quadrado (para captar o formato da curva dos retornos associados à evolução da experiência, esperando-se coeficiente negativo que indique a concavidade dessa função), anos de estudo (buscando avaliar o impacto do estoque de capital humano geral), anos de experiência na atual função (também como proxy do capital humano específico) e dummies para o gênero do indivíduo (que assume o valor de um se for homem), cor (um se for branco), a fim de captar os efeitos da discriminação, para o estado em que a pessoa trabalha (assumindo valor igual a um para o estado em que a pessoa reside, sendo a dummy de controle o Distrito Federal) com o objetivo de avaliar o impacto das características locais dos mercados de trabalho sobre os salários (a comparação se dará entre o Distrito Federal e cada um dos estados, mas não entre eles) e para a filiação do trabalhador a um sindicato (que assumirá valor igual a um, se for filiado a alguma entidade desse tipo).

Não foram incluídas variáveis referentes ao ramo de ocupação em que a pessoa atua para reduzir o risco de endogeneidade das variáveis explicativas. Por exemplo, um determinado ramo pode pagar melhores salários, porque demanda pessoas mais qualificadas, o que já estaria sendo captado pelas demais variáveis, e não apenas porque a estrutura de mercado ou produtiva defrontada pelas empresas que nele atuam é distinta, o que poderia porventura facilitar a prática de salários mais elevados neste ramo.

Essas variáveis explicativas correspondem, na verdade, a controles que buscam avaliar o impacto que características demográficas, produtivas e institucionais exercem sobre os salários das pessoas. A última variável a ser incluída nesse modelo - e a mais relevante - é a dummy referente ao setor que a pessoa trabalha (que assume o valor de um se for no setor público). Seu coeficiente estará mensurando o diferencial percentual entre as médias geométricas de salário praticado nos dois setores para trabalhadores com características pessoais idênticas (já que os demais fatores que influem nesse diferencial já estarão controlados, pela inclusão de outras dummies, que mensurarão os efeitos que as diversas características dos trabalhadores exercem sobre o diferencial de salários). Dessa 
forma, essa dummy captará o diferencial controlado de salários entre os servidores públicos e os trabalhadores do setor privado.

O formato da equação inicial será o seguinte ${ }^{14}$ :

Ln $\mathrm{W}_{\mathrm{i}}=\mathrm{a}+\left(\mathrm{b} *\right.$ setor $\left._{\mathrm{i}}\right)+\left(\mathrm{c} *\right.$ idade $\left._{\mathrm{i}}\right)+\left(\mathrm{d} *\right.$ idade $\left._{\mathrm{i}}^{2}\right)+\left(\mathrm{e} *\right.$ gênero $\left._{\mathrm{i}}\right)$ $+(\mathrm{f} *$ anos de estudo $\mathrm{i})+\left(\mathrm{g} *\right.$ cor $\left._{\mathrm{i}}\right)+\left(\mathrm{h} *\right.$ anos de experiência $\left.\mathrm{i}_{\mathrm{i}}\right)+$ $\left(\mathrm{i} *\right.$ estado $\left._{\mathrm{i}}\right)+\left(\mathrm{j} *\right.$ sindicato $\left._{\mathrm{i}}\right)$,

onde:

Ln $\mathrm{W}_{\mathrm{i}}=$ logaritmo natural do salário do indivíduo i, ajustado para o número de horas trabalhadas,

$\mathrm{a}=$ constante,

setor $=d u m m y$ indicativa do setor em que o indivíduo i atua (público ou privado),

idade $=$ idade do indivíduo $\mathrm{i}$,

idade $^{2}=$ idade ao quadrado do indivíduo i,

gênero $=$ dummy referente ao gênero do indivíduo $\mathrm{i}$,

anos de estudo = número de anos de estudo do indivíduo i,

cor $=$ dummy referente à cor do indivíduo $\mathrm{i}$,

anos de experiência $=$ número de anos, que o indivíduo i tem naquele emprego,

estado $=$ dummy referente ao estado em que o indivíduo i trabalha (sendo criada uma para cada estado),

sindicato $=$ dummy referente à filiação do indivíduo i a algum sindicato.

As regressões para os anos considerados (1993, 1996 e 1999) foram realizadas com base nessa equação, pelo método dos mínimos quadrados simples, sendo que foram incluídos na amostra de cada uma delas os indivíduos que trabalham no setor privado e os pertencentes ao segmento do setor público considerado no respectivo cálculo.

A tabela 9 reporta os diferenciais controlados de salário entre os trabalhadores do setor público e privado que resultaram das regressões efetuadas a partir da equação definida anteriormente. Nota-se inicialmente que os diferenciais reduzem-se substancialmente em relação aos registrados na tabela 8 , aos quais não havia sido adicionado qualquer tipo de controle relativo às características pessoais. Logo, as diferenças na composição da força de trabalho entre os dois setores explicam uma parcela significativa do diferencial bruto de salário (não controlado).

Ainda assim o acréscimo das variáveis de controle à análise mostra que, mesmo considerando as diferenças nas características demográficas e produtivas dos trabalhadores nos dois setores, o diferencial salarial permanece positivo para os funcionários públicos na maioria dos casos analisados - é negativo, em 1993 e 1996, para os servidores municipais e estatisticamente nulo, apenas em 1999, para os municipais. Portanto podemos reconhecer a existência de segmentação entre os dois mercados, 
já que indivíduos com características semelhantes não recebem remunerações iguais nos dois setores.

Tabela 9: Diferencial salarial entre os setores público/privado controlado (em \%)

\begin{tabular}{l|c|c|c}
\hline & $\mathbf{1 9 9 3}$ & $\mathbf{1 9 9 6}$ & $\mathbf{1 9 9 9}$ \\
\hline Privado & - & - & - \\
\hline Público & 7 & 8 & 16 \\
\hline Federal & 51 & 45 & 56 \\
\hline Estatutário + Militar & 41 & 50 & 65 \\
\hline Estatutário & 54 & 61 & 76 \\
\hline Militar & 14 & 29 & 47 \\
\hline Celetista & 71 & 40 & 44 \\
\hline Estadual & 8 & 8 & 17 \\
\hline Estatutário & 2 & 7 & 16 \\
\hline Celetista & 16 & 12 & 19 \\
\hline Municipal & -13 & -7 & 1 \\
\hline Estatutário & -10 & -4 & 1 \\
\hline Celetista & -17 & -10 & 1 \\
\hline Total estatutário & 7 & 10 & 17 \\
\hline Total celetista & 9 & 6 & 14 \\
\hline Total militar & 14 & 29 & 47 \\
\hline
\end{tabular}

* 1999 não significativo a 5\%.

Diversas análises sobre os diferenciais de salário existentes entre os trabalhadores dos dois setores concluem que, apesar de, em média, o setor público pagar salários maiores aos seus funcionários que o setor privado, este comportamento não seria uniforme quando a força de trabalho é estratificada de acordo com os diversos níveis de qualificação. Os trabalhadores mais qualificados receberiam salários menores no setor público, enquanto os menos qualificados receberiam remunerações superiores às observadas para seus pares no setor privado. Com isso, o leque salarial seria menor no setor público (e provavelmente a distribuição da renda seria menos desigual), mas em compensação o sistema remuneratório tornar-se-ia menos eficiente com relação à atração e retenção de funcionários qualificados.

Existem algumas formas de proceder a uma verificação empírica dessa afirmação. Uma delas corresponde à análise por grupos de ocupação, supondo que, para exercê-las, é necessário determinado estoque de capital humano. Essa estratégia encontra algumas dificuldades de implementação 
em relação à identificação de grupos semelhantes e, em decorrência, comparáveis no setor público e privado. Por exemplo, é difícil definir a função que um juiz, um fiscal ou um policial ocupariam no setor privado, dado o seu estoque de capital humano geral e específico. Da mesma forma, seria necessário supor que um gerente de determinada área que hoje atua no setor público teria seu capital humano específico valorizado da mesma forma no setor privado, para desempenhar atividades de chefia semelhantes.

Outra estratégia para avaliar a questão colocada corresponderia à classificação dos trabalhadores por grupos de anos de estudo. Essa opção, por sua vez, implicaria a hipótese, a qual vem sendo adotada, ainda que de forma implícita, durante os testes realizados nesta seção, de que a valoração distinta do capital humano geral dos trabalhadores, caso ocorra, já corresponde a uma forma de segmentação entre os dois mercados. Essa estratégia parece, de toda forma, incorrer em quantidade menor de suposições que a anterior. Apesar de, no serviço público, o alcance de um nível maior de escolaridade não implicar, a curto prazo, promoções ou ocupação de posições mais qualificadas, dado que a mudança de cargo exige a participação em processo seletivo público, a médio prazo a correlação entre escolaridade e ocupação parece ser bastante razoável.

Portanto, neste estudo, vamos proceder à análise estratificada por intervalos de anos de estudo, para avaliar se o diferencial controlado de salários se altera para cada um dos grupos. Os trabalhadores serão divididos de acordo com o seu nível de escolaridade: 0 a 4 anos de estudo, 5 a 8, 9 a 11 e 12 ou mais. Os demais controles adotados nas equações anteriores serão mantidos e os testes serão realizados para os servidores públicos federais (subdivididos em estatutários, celetistas e militares), estaduais e municipais, como na análise sobre o perfil da força de trabalho.

Tabela 10: Diferencial salarial entre os setores federal estatutário/privado controlado e segmentado por anos de estudo (em \%)

\begin{tabular}{l|c|c|c}
\hline & $\mathbf{1 9 9 3}$ & $\mathbf{1 9 9 6}$ & $\mathbf{1 9 9 9}$ \\
\hline 0-4 anos de estudo & 87 & 109 & 135 \\
\hline 5-8 anos de estudo & 68 & 63 & 101 \\
\hline 9-11 anos de estudo & 47 & 58 & 60 \\
\hline 12 ou mais anos de estudo & 29 & 31 & 48 \\
\hline Geral & 54 & 61 & 76 \\
\hline Difer. em pontos percentuais entre & & & \\
0-4 e mais de 12 anos de estudo & 59 & 78 & 87 \\
\hline
\end{tabular}


Tabela 11: Diferencial salarial entre os setores

federal celetista/privado controlado e segmentado por anos de estudo (em \%)

\begin{tabular}{l|c|c|c}
\hline & $\mathbf{1 9 9 3}$ & $\mathbf{1 9 9 6}$ & $\mathbf{1 9 9 9}$ \\
\hline 0-4 anos de estudo & 59 & 45 & 2 \\
\hline 5-8 anos de estudo & 59 & 27 & 32 \\
\hline 9-11 anos de estudo & 78 & 39 & 45 \\
\hline 12 ou mais anos de estudo & 41 & 18 & 29 \\
\hline Geral & 71 & 40 & 44 \\
\hline $\begin{array}{l}\text { Difer. em pontos percentuais entre } \\
\text { 0-4 e mais de 12 anos de estudo }\end{array}$ & 18 & 27 & -27 \\
\hline
\end{tabular}

*** 1999 não significativo a 5\%.

Tabela 12: Diferencial salarial entre os setores federal militar/privado controlado e segmentado por anos de estudo (em \%)

\begin{tabular}{l|c|c|cc}
\hline & $\mathbf{1 9 9 3}$ & $\mathbf{1 9 9 6}$ & $\mathbf{1 9 9 9}$ & \\
\hline 0-4 anos de estudo & 31 & 20 & 114 & $* *$ \\
\hline 5-8 anos de estudo & 5 & 41 & 62 & $*$ \\
\hline 9-11 anos de estudo & 24 & 34 & 47 & \\
\hline 12 ou mais anos de estudo & 10 & 22 & 44 & $*$ \\
\hline Geral & 14 & 29 & 47 & \\
\hline $\begin{array}{l}\text { Difer. em pontos percentuais entre } \\
\text { 0-4 e mais de 12 anos de estudo }\end{array}$ & 21 & -2 & 69 & \\
\hline
\end{tabular}

* 1993 não significativo a 5\%.

** 1996 não significativo a 5\%.

Tabela 13: Diferencial salarial entre os setores estadual/privado controlado e segmentado por anos de estudo (em \%)

\begin{tabular}{l|c|c|cc}
\hline & $\mathbf{1 9 9 3}$ & $\mathbf{1 9 9 6}$ & $\mathbf{1 9 9 9}$ \\
\hline 0-4 anos de estudo & 31 & 22 & 26 & \\
\hline 5-8 anos de estudo & 21 & 11 & 23 & \\
\hline 9-11 anos de estudo & 9 & 12 & 23 & \\
\hline 12 ou mais anos de estudo & -17 & -11 & -3 & $* * *$ \\
\hline Geral & 8 & 8 & 17 & \\
\hline Difer. em pontos percentuais entre & & & & \\
0-4 e mais de 12 anos de estudo & 48 & 33 & 29 & \\
\hline
\end{tabular}

*** 1999 não significativo a 5\%. 
Tabela 14: Diferencial salarial entre os setores municipal/privado controlado e segmentado por anos de estudo (em \%)

\begin{tabular}{|c|c|c|c|c|}
\hline & 1993 & 1996 & 1999 & \\
\hline 0-4 anos de estudo & -16 & -14 & -4 & \\
\hline 5-8 anos de estudo & -14 & -7 & -3 & $* * *$ \\
\hline 9-11 anos de estudo & -11 & -5 & 5 & \\
\hline 12 ou mais anos de estudo & -26 & -14 & -9 & \\
\hline Geral & -13 & -7 & 1 & $* * *$ \\
\hline $\begin{array}{l}\text { Difer. em pontos percentuais entre } \\
0-4 \text { e mais de } 12 \text { anos de estudo }\end{array}$ & 10 & 0 & 5 & \\
\hline
\end{tabular}

Os resultados das regressões controladas por anos de estudo mostram que, ao longo da década de 1990, o diferencial de salários evoluiu para os diversos segmentos do setor público estratificados por nível de escolaridade, com exceção dos federais celetistas, sobre os quais recaiu parcela significativa do ajuste fiscal, conforme já discutido.

Para os federais estatutários, todos os estratos analisados apresentam diferencial salarial positivo e crescente ao longo do período (sempre considerando a inclusão dos controles anteriormente descritos). Para os servidores federais celetistas, o diferencial permaneceu positivo para todos os estratos de escolaridade, mas em 1999 era menor que o observado em 1993, notadamente para os menos escolarizados. Em relação aos militares, os resultados também indicam aumento do diferencial durante os anos 90, apesar de, em alguns casos, os resultados observados não serem estatisticamente significativos. Dada a magnitude desses últimos, tal comportamento deve decorrer do tamanho e da acentuada oscilação dos valores da amostra.

Em relação aos servidores estaduais, a tendência observada é compatível com o resultado desejado, pois os estratos de servidores cujo nível de escolaridade é mais elevado apresentam evolução mais significativa do respectivo diferencial ao longo da década. Enquanto o diferencial se reduz para os funcionários que possuem de 0 a 4 anos de estudo, permanece praticamente estável para os servidores com 5 a 8 anos de estudo e aumenta significativamente para os mais escolarizados, que possuem de 9 a 11 e 12 ou mais anos de estudo, sendo que neste último caso o diferencial anteriormente negativo transforma-se em estatisticamente nulo. Logo, esses dados permitem inferir que o leque salarial no setor público estadual tem se ampliado e, com isso, a atual estrutura remuneratória dessa esfera de governo tem sido mais eficaz para atrair e reter funcionários qualificados. 
Para os servidores municipais, observa-se evolução para todos os grupos ao longo do período analisado. Os diferenciais eram fortemente negativos e foram reduzidos, tornados estatisticamente nulos ou ainda positivo, em um caso, ao final da década. Somente para os servidores mais escolarizados (12 ou mais anos de estudo) é observado um diferencial negativo mais relevante, ainda assim da ordem de aproximadamente $10 \%$ e bem inferior ao observado em 1993. Este segmento e o dos servidores municipais com 0 a 4 anos de estudo (este último, em magnitude bem inferior) são os únicos que apresentam diferencial negativo em 1999. Nos demais segmentos analisados, o salário é superior na administração pública para pessoas com características semelhantes.

Ressalta-se que, a exemplo do verificado na análise do perfil e das ocupações das pessoas incluídas na amostra, o setor público municipal é o grupo que apresenta características mais próximas das observadas no setor privado, uma vez que os menores diferenciais entre os estratos considerados foram registrados para este grupo e, logo, os seus salários são os que mais se aproximam dos praticados no setor privado (após a inclusão de controles para as características pessoais e institucionais).

Assim, os diferenciais encontrados em 1999 para a relação entre os salários dos servidores municipais e os do setor privado fornecem indícios mais fortes de que as características dos mercados de trabalho para estes grupos encontram-se muito próximas, ou menos desiguais, que para os demais segmentos do funcionalismo público. É possível que o mercado de trabalho para os servidores municipais seja bastante influenciado pelas condições locais, da mesma forma que o mercado de trabalho do setor privado, e também esteja mais relacionado à própria dinâmica do mercado deste setor.

No caso dos servidores federais estatutários e estaduais, observase que o diferencial é maior para os grupos menos qualificados; logo, pode-se afirmar que seus integrantes recebem melhores salários relativos (tendo como base de comparação os recebidos por trabalhadores com as mesmas características no setor privado) que os componentes dos grupos mais qualificados ${ }^{15}$.

Os levantamentos e testes realizados nas seções anteriores permitiram afirmar que o nível de emprego público permaneceu praticamente estável ao longo da década de 1990, enquanto o salário médio dos servidores cresceu durante o período, inclusive a uma taxa superior à observada no setor privado; logo, governantes e burocratas optaram, durante o processo de ajuste pelo qual vem passando o setor público, por proteger mais os níveis salariais que o do emprego. Dado esse cenário, o diferencial salarial bruto (sem controles) entre o setor público e o privado elevou-se ao longo da década. 
Ao longo desta seção, foram adicionados controles ao cálculo do diferencial e observou-se comportamento semelhante. Como a inclusão desses controles resulta em queda considerável na magnitude do diferencial, as especificidades da composição da força de trabalho explicam parcela considerável deste último. A estratificação da análise por intervalos de anos de estudo também apontou evolução do diferencial público/privado ao longo da década, sendo que, ao final do período, havia apenas um grupo no setor público, entre os analisados, cujo diferencial ainda era significativamente negativo. Em alguns segmentos, os diferenciais maiores foram encontrados para os grupos com menor escolaridade.

Conseqüentemente, pode-se afirmar que, mesmo após a inclusão de diversos tipos de controle - isto é, considerando diversos critérios que possibilitam comparar trabalhadores com características semelhantes -, os salários no setor público são superiores aos pagos no setor privado. Mais que isso, uma vez que os salários controlados são distintos nos dois setores, caracteriza-se a segmentação entre os dois mercados.

Os dados indicam que a questão do nível salarial dos funcionários públicos foi relativamente equacionada ao longo da década de 1990, principalmente se considerarmos que a comparação com as remunerações pagas no setor privado é um parâmetro satisfatório de análise da adequação dos salários praticados no setor público. Assim, mais que discutir os níveis salariais, atualmente é importante avaliar se o sistema remuneratório, apesar de, em média, resultar em pagamento de bons salários (fato que representa um incentivo ao desempenho dos funcionários), apresenta distorções internas que desestimulem a atração, o desenvolvimento e a retenção de bons funcionários.

A próxima seção discutirá algumas distorções do sistema remuneratório do setor público evidenciadas nos últimos anos, com ênfase para o caso dos servidores federais estatutários, as medidas que foram adotadas para reduzi-las ou eliminá-las e sugestões sobre aspectos que precisam ser equacionados no futuro.

\section{A evolução do sistema remuneratório ao longo da década de 1990 e sugestões para aprimorá-lo}

A estrutura remuneratória do setor público federal, mais especificamente dos servidores estatutários, sofreu evolução significativa nos últimos anos, a qual, até meados dos anos 90, apresentava diversas distorções, sem considerar a questão do nível salarial, já discutida na seção anterior, tais como:

a) quantidade muito grande de parcelas salariais; 
b) amplitude salarial das carreiras muito estreita, o que reduzia consideravelmente o estímulo à progressão;

c) participação exagerada das gratificações que vinham sendo criadas ou reajustadas na composição do salário, constituindo cerca de $60 \%$ dos vencimentos do servidor, chegando a $90 \%$ em alguns casos, fato que inibe uma avaliação de desempenho adequada;

d) ausência de correlação entre a progressão na carreira (que implica em melhoria salarial), o desempenho e o acúmulo de competências por parte do servidor;

e) reduzida variância das avaliações de desempenho para fins de cálculo de pagamento da gratificação variável, bem como a sua freqüente concessão pelo valor máximo;

f) existência de vínculo entre todas as reestruturações salariais de carreiras, que envolvem ganhos reais e alinhamento com os salários pagos no setor privado, por exemplo, e as correções salariais das aposentadorias, o que inibe fortemente a prática de reajustes pois o seu impacto fiscal é muito relevante;

g) existência de estruturas remuneratórias diferentes para cargos que possuem atribuições semelhantes, mas pertencem a carreiras distintas;

h) pagamento por ordem judicial, cujo mérito muitas vezes já havia sido anteriormente julgado inconstitucional, de parcelas ou correções salariais que distorcem completamente a hierarquia remuneratória.

A partir de 1995, a política remuneratória visou corrigir essas distorções. Os salários deixaram de ser automaticamente corrigidos pela inflação passada, uma vez que a economia brasileira passava por um processo de estabilização e a indexação dos salários prejudicaria esse processo. Como estudos realizados à época observaram que havia desalinhamento salarial significativo em relação às remunerações pagas no setor privado, optou-se por balizar as correções dos vencimentos no setor público pelos valores praticados para os cargos equivalentes no setor privado a fim de reduzir tal defasagem. Essa passou a ser a principal diretriz dos reajustes salariais no setor público federal.

Ao longo do período em que vem sendo praticada a atual política remuneratória, foram obtidos os seguintes avanços:

a) o número de parcelas salariais foi reduzido mediante a incorporação de gratificações ao vencimento básico;

b) a amplitude salarial das carreiras foi alargada;

c) a participação da gratificação de desempenho foi reduzida para cerca de $30 \%$ dos vencimentos do servidor na maioria dos casos;

d) as correções tiveram como meta a redução das disparidades em relação aos valores praticados no setor privado, ainda que, em algumas vezes, as pressões políticas, se bem-sucedidas em virtude do poder de barganha das categorias envolvidas no processo de negociação, podem 
alterar, de forma esporádica, a consistência estabelecida pela diretriz de ordem mais geral;

e) a reestruturação salarial das diversas carreiras buscou, dentro dos limites legais, desvincular as correções salariais dos ativos das concedidas aos inativos, mediante a eliminação da regra que concedia a estes o pagamento automático do valor máximo possível da gratificação de desempenho;

f) início do processo de aproximação das remunerações devidas a servidores que desempenham funções semelhantes, mas pertencem a carreiras distintas, como no caso da fiscalização;

g) diversas sentenças judiciais concedidas sem o amparo de decisão do Supremo Tribunal Federal vêm sendo questionadas.

Apesar desses diversos avanços, ainda existem pontos que merecem maior atenção dos gestores da política de recursos humanos. O primeiro refere-se à questão da progressão nas carreiras, a qual sempre resulta em melhoria salarial, mas somente em alguns casos implica aquisição de número maior de atribuições e responsabilidades, pois, na maioria das situações, está vinculada ao tempo de serviço, e não ao desempenho, fazendo com que o servidor não seja incentivado a perseguir seu aperfeiçoamento. É fundamental, como estímulo ao próprio desenvolvimento profissional dos servidores, que as avaliações de desempenho, das competências adquiridas e da possibilidade de acúmulo de novas atribuições sejam os critérios mais relevantes para progressão em todas as carreiras. As melhorias remuneratórias associadas à promoção estão se tornando mais relevantes para o servidor, à medida que a amplitude salarial das diversas carreiras vem aumentando.

Por implicar resistências, uma vez que a mudança eliminaria o caráter quase automático da progressão, deve-se iniciar processo de negociação para alterar as regras atuais e vinculá-las ao desempenho e às competências adquiridas. Um dos caminhos seria instituir essa sistemática inicialmente nas organizações que apóiam esse princípio de forma mais incisiva e, aos poucos, ir rompendo o seu vínculo com a antiguidade nas demais. As atuais características da progressão não podem ser mantidas em cenário que persegue a modernização da gestão de recursos humanos.

Além disso, é importante aprimorar os mecanismos de avaliação de desempenho para fins de cálculo da gratificação variável. Em relação ao seu componente individual, deve-se estimular o efetivo envolvimento das chefias no processo de avaliação de seus subordinados, de forma, inclusive, a provocar maior variância entre as pontuações resultantes, a qual reflete, de forma mais apropriada, o desempenho dos servidores, pois é muito difícil que todos apresentem dedicação semelhante. Para tal, é necessário que a avaliação ocorra a partir da definição de metas e resultados esperados, inseridas no contexto do planejamento estratégico mais geral 
da organização, sobre os quais as chefias sejam também cobradas, bem como a participação relativa da gratificação na composição da remuneração do servidor seja ainda mais reduzida.

Em relação ao componente institucional da avaliação, é fundamental priorizar a sua disseminação, bem como o estabelecimento de vínculo estreito entre os seus resultados e o cumprimento das metas definidas pela organização, as quais podem ser formuladas a partir de instrumentos existentes, quais sejam o PPA ou o Programa de Qualidade, da forma como já vêm sendo estimulados pelos gestores da política de recursos humanos.

Por último, deve-se ressaltar a necessidade de criar mecanismos que possibilitem remunerar, de forma diferenciada, os servidores ou integrantes de órgãos que apresentem capacitação, competências e desempenho diferenciados, independentemente da carreira à qual pertençam. Dito de outra forma, é importante criar mecanismos de estímulo salarial que estejam desvinculados da estrutura remuneratória das carreiras e possibilitem recompensar, de forma adequada e isolada, servidores e instituições mais eficientes.

Esses mecanismos, por sua vez, não podem implicar a eliminação da uniformidade de regras salariais de determinada carreira, sob pena de gerar diversas demandas judiciais. Por outro lado, devem resultar em maior responsabilização dos gerentes de linha - fundamental para o desenvolvimento de política eficiente de recursos humanos, os quais possuem atualmente pouca margem e instrumentos para gerir o desenvolvimento profissional de seus funcionários, fato que certamente contribui para o seu reduzido envolvimento com o tema - e evitar a possibilidade de desmandos, desvios e, em decorrência, o surgimento de outras distorções em sua utilização.

Esta dicotomia entre a necessidade de flexibilização e, ao mesmo tempo, de uniformidade das regras de remuneração não apresenta solução simples. Porém, um instrumento que poderá facilitar esse processo é a criação de um bônus, a ser distribuído para as instituições que alcançarem suas metas de forma eficiente, cujo montante seria alocado entre os diversos instrumentos da política de recursos humanos. Um desses instrumentos seria uma recompensa na forma de ganhos extraordinários, que seriam distribuídos esporadicamente - por exemplo, uma vez por ano -, a fim de não configurar parcela salarial.

A decisão sobre a alocação dos recursos destinados ao bônus caberia aos dirigentes da instituição, enquanto a Seges apenas definiria a sua distribuição entre os órgãos e alguns limites para sua repartição interna. Ao responsabilizar os gerentes pela sua repartição interna e deles cobrar intensamente resultados, a possibilidade de ocorrência de distorções e desvios é sensivelmente reduzida, pois essa prática seria forte desestímulo à atuação dos servidores. 
A introdução do bônus permitiria: a) o vínculo de forma mais estreita da gestão de recursos humanos à estratégica da empresa, uma vez que o aprimoramento desse vínculo também é fator condicionante do sucesso da gestão de pessoas, que possibilitará à área de recursos humanos ser considerada parceira que agrega valor às demais; b) o surgimento de forte instrumento incentivador que os gerentes poderiam adotar em relação aos funcionários, possibilitando diferenciar os que se destacam, flexibilizar a gestão de recursos humanos e, ao mesmo tempo, manter a uniformidade das regras de salário e progressão, entre outras.

Essa sugestão não visa, em hipótese alguma, criar uma panacéia no sistema remuneratório, mas apenas indicar um possível mecanismo de flexibilização que, ao mesmo tempo, seja incentivo ao desempenho e mantenha a estrutura salarial das diversas carreiras e, por conseqüência, os princípios de isonomia previstos nela.

Os gerentes terão de, para aplicar esse instrumento, estar mais envolvidos na gestão do desenvolvimento profissional de seus subordinados. E essa é uma das diretrizes mais relevantes de uma política remuneratória e, de forma mais geral, de recursos humanos que pretende ser eficiente e estar associada aos princípios da gestão empreendedora.

\section{Conclusões}

Este artigo buscou demonstrar, primeiramente, que, ao longo da década de 1990, o emprego público, sob a ótica agregada, manteve-se estável, mas o comportamento foi distinto quando são analisados os diversos níveis de governo e regimes de trabalho, com destaque para a redução observada entre os celetistas - em virtude da privatização e da disseminação do regime jurídico único - e o crescimento verificado entre os servidores municipais, devido à evolução do volume de recursos transferidos e de serviços cuja execução foi repassada a esta esfera de governo.

A análise das características da força de trabalho indicou que os funcionários do setor público possuem, em média, ocupações menos operacionais e nível de escolaridade, idade e tempo de serviço médios maiores que seus pares do setor privado. Esses resultados são forte indicativo de que o perfil da força de trabalho no setor público é mais qualificado que o observado em relação aos trabalhadores do setor privado. Entre os segmentos do setor público, os servidores municipais são aqueles cujas características mais se aproximam das registradas no setor privado.

Em decorrência das diferenças entre os perfis analisados, os salários médios pagos no setor público, para cada um dos segmentos analisados, são superiores aos pagos no setor privado, com algumas exceções. A fim de isolar o efeito das diferenças entre salários, em função das distintas 
características entre os trabalhadores dos dois mercados, foram calculadas

regressões nas quais adicionaram-se controles que permitem a comparação entre os trabalhadores dos dois setores que possuam características demográficas e produtivas semelhantes.

Mesmo com a adição de tais controles, notou-se que o diferencial de salários observado entre o setor público e o privado cresceu ao longo da década e, mesmo para a maioria dos casos em que o diferencial era negativo no início da década, tornou-se positivo ou nulo em 1999. Logo, entre os trabalhadores com idênticas características de ambos setores, recebem, em geral, maiores remunerações os do setor público. Esse resultado permite inferir que a questão dos níveis salariais na administração pública já estaria relativamente equacionada, pois, mesmo para os grupos que possuem maior escolaridade, com exceção dos servidores municipais, os salários são maiores para pessoas que possuam características demográficas e produtivas semelhantes.

A comparação entre os salários praticados em ambos setores demonstrou, mais uma vez, que o mercado de trabalho público municipal, entre os segmentos analisados, é o que possui características mais próximas das detectadas no setor privado. É muito provável que essa semelhança seja explicada por uma possível influência relevante, sobre ambos, das condições econômicas e sociais locais. Futuros estudos devem ser direcionados à análise dessa hipótese.

Por fim, restariam outras distorções no sistema remuneratório do setor público que precisariam ser eliminadas ou, ao menos, reduzidas. Algumas estão caminhando no sentido de serem solucionadas, enquanto outras ainda carecem de maior atenção e medidas direcionadas à sua solução. Os mecanismos que apresentam as maiores deficiências no presente são a avaliação de desempenho e os critérios para progressão na carreira - que implicam, no primeiro caso, a definição da parcela variável do salário e, no segundo, de melhorias salariais permanentes para os servidores - e a inexistência de mecanismos que permitam remunerar, de forma diferenciada, pessoas ou órgãos que possuam competências e apresentem desempenho destacados e, ao mesmo tempo, impliquem maior envolvimento e responsabilização das chefias na avaliação, desenvolvimento profissional e definição da remuneração de seus funcionários, sem possibilitar práticas indevidas. A última seção deste trabalho apresentou algumas propostas para solucionar esses problemas.

A partir do exposto anteriormente, é possível afirmar que a política remuneratória em vigor é eficiente para atrair novos funcionários, pois o Poder Executivo federal paga bons salários aos seus servidores. Não parece, entretanto, ser ela muito eficiente em relação à motivação para que as pessoas se desenvolvam profissionalmente e adquiram as competências necessárias, pois as regras de progressão, à qual estão associadas 
melhorias salariais, ainda estão demasiadamente associadas ao tempo de serviço do servidor e é possível atingir o patamar máximo da carreira bem antes da época de aposentar-se.

Quanto à retenção, a política remuneratória tem se mostrado adequada em relação às posições cujos salários são superiores aos pagos no setor privado, as quais constituem ampla maioria. Soma-se a esse fato a existência da estabilidade e da aposentadoria com proventos integrais, o que torna a taxa de desligamentos, na Administração Pública federal, bastante reduzida, a qual correspondeu a 2,3\% da força de trabalho no período entre 1998 e 2001, sem considerar os afastamentos decorrentes de aposentadoria ${ }^{16}$. A retenção é menor apenas para os cargos dos primeiros escalões, pois neste caso não há como competir, a longo prazo, com as vantagens oferecidas pelo mercado privado, a não ser que a pessoa apresente forte preferência pela atuação no setor público.

Em última análise, os fatores preponderantes para a definição da remuneração individual, ou, dito de outra forma, do salário relativo do servidor, devem ser suas competências - experiência, formação, habilidades adquiridas -, as tarefas a ele atribuídas e o seu desempenho. Os gestores da política de recursos humanos vêm pautando sua atuação nesse sentido, mas ainda há muito a ser realizado. Esse é um desafio que não está circunscrito a um curto prazo.

\section{Notas}

1 Os dados de nível de emprego e massa salarial foram calculados a partir da expansão da amostra. O salário médio, por sua vez, calculado a partir dos salários individuais ajustados para as horas trabalhadas, não decorre de expansão da amostra e, portanto, não corresponde à exata divisão da massa salarial pelo emprego total.

2 Em 2000 a PNAD não foi efetuada em virtude da realização do censo.

3 Não existem trabalhadores ou empregadores que trabalham por conta própria no setor público, e os concursos públicos e processos de seleção simplificados impõem como requisito de ingresso, em geral, a idade mínima de 18 anos. Adicionalmente, não é usual que o servidor público exerça suas atividades nas chamadas áreas rurais, a não ser em casos bastante isolados, como a fiscalização agrícola ou de fronteiras.

4 Está implícita neste cálculo a suposição de que o valor do salário-hora não se altera de acordo com o número de horas trabalhadas, pelo menos até o limite de 44 horas. Na prática, isso é verdade para o caso brasileiro, pois até esse limite a legislação estabelece o mesmo salário-hora e, somente acima dele, o pagamento de horas extras.

5 Dados do IBGE de 1997 apontam que os estados com menor renda per capita naquele ano eram Tocantins, Maranhão, Piauí, Paraíba, Alagoas, justamente aqueles em que a participação do emprego público no emprego total é inferior somente à dos ex-territórios. 
Como a renda per capita não se altera substancialmente em curto prazo, podemos estimar que essa situação perdurou até 1999, no mínimo, último ano de nossa análise.

6 A composição desse grupo não será analisada detalhadamente, pois seus servidores, conforme já afirmado, trabalham, em sua grande maioria, nas empresas públicas, e este estudo está mais direcionado à análise da evolução da força de trabalho na administração direta, nas autarquias e fundações. Em relação aos servidores estaduais e municipais, por sua vez, os dois regimes de trabalho - estatutário e celetista - coexistem nas organizações para as quais o foco deste trabalho está direcionado e não haverá distinção entre eles.

7 Os governos, notadamente o federal, vêm se esforçando para reduzir a participação de funcionários das áreas de suporte na composição da força de trabalho, mas esse é um processo lento, pois não há a intenção de provocar desligamentos em massa e existem diversas barreiras legais para alteração imediata das atividades exercidas pelas pessoas. É possível, entretanto, uma mudança gradual, que não implique alteração significativa das atribuições, baseada na requalificação dos servidores e na modificação do perfil da força de trabalho, à medida que aqueles que exercem as atividades de suporte vão se aposentando.

8 Os servidores municipais recebiam salários relativamente inferiores no início da década, mas, ao seu final, já recebiam remunerações equivalentes ou superiores.

9 E explicado também pela criação do Regime Jurídico Único, uma vez que, na administração direta, nas autarquias e fundações, a vaga de um celetista que se aposentava não era preenchida, quando fosse o caso, por outro servidor contratado sob este regime de trabalho, e sim pelo estatutário.

${ }^{10}$ Os resultados dos trabalhos de Macedo e Barros et al. vão demonstrar, partindo de diferentes amostras (RAIS ou PNADs) e períodos diferentes, que, mesmo após a inclusão de controles, o salário médio dos servidores é mais elevado que o pago no setor privado. Gill et al. (1997) também apresentam semelhante conclusão. O estudo de Urani e Ramalho (1995), por sua vez, vai analisar o diferencial por grupos educacionais e é o único que obtém conclusões distintas, mostrando que, ao longo da década de 80 , somente o grupo de servidores que possui menos de um ano de escolaridade apresentou diferencial salarial positivo, sendo negativo e crescente para os demais grupos, à medida que fossem incluídos na análise os mais escolarizados.

${ }^{11}$ A influência das diversas características pessoais na formação dos salários, por sua vez, também depende da oferta e da demanda em relação a cada uma delas.

${ }^{12}$ Uma outra variável que também poderá avaliar o impacto de aspectos não pecuniários na formação dos salários é o número de anos de serviço numa mesma empresa, que, além de refletir o capital humano específico da pessoa, também pode corresponder a um indicador da taxa de rotatividade da empresa.

${ }^{13}$ Notar que as duas variáveis não possuem significado semelhante, pois na verdade o grau de sindicalização é apenas uma das variáveis que contribuem para a definição do poder de barganha dos trabalhadores e, neste sentido, está sendo utilizado como proxy.

${ }^{14}$ Esse formato, que utiliza o modelo semilog, corresponde ao usualmente adotado para equações de salário.

${ }^{15}$ A diferença em pontos percentuais, por sua vez, é um primeiro indicativo, ainda que parcial, da diferença entre os leques salariais no setor público e no privado. A redução da diferença em pontos percentuais corresponderia a um sinal de que provavelmente a diferença entre as amplitudes dos leques salariais nos dois setores estaria se reduzindo.

${ }^{16}$ A taxa de desligamentos foi calculada a partir da seguinte fórmula: número de funcionários ao final de um determinado ano (-) número de funcionários no início deste mesmo ano (+) contratações no ano (-) aposentadorias no ano (/) número de funcionários no início do mesmo ano. 
Altonj, Joseph G.; Blank, Rebecca M. Race and gender in the labor market. In: AsHenFelter, O.; Layard, R. (Ed.) Handbook of labor economics. Elsevier Science Publishers, 1999. v. 3. ASHENFELTER, O.; LAYARD, R. (Ed.). Handbook of labor economics. Elsevier Science Publishers BV, 1986. v. 1 e 2 .

. Handbook of labor economics. Elsevier Science Publishers BV, 1999.

V. 3 .

Barros, Ricardo P.; Foguel, Miguel N.; MendonçA, Rosane. The wage gap between the public and private sectors in Brazil. In: Série Seminários, n. 13/97, Rio de Janeiro, IPEA, 1997.

BECKER, Gary. Human capital. Chicago: The University of Chicago Press, 1964.

BORJAs, George J. Wage determination in the federal government: the role of constituents and bureaucrats. In: Journal of Political Economy, 88(6), 1980.

Bresser Pereira, Luiz Carlos. Crise econômica e reforma do Estado no Brasil. São Paulo: Editora 34, 1996.

CAIN, Glen G. The economic analysis of labor market discrimination: a survey. In: Ashenfelter, O.; LAyARD, R. (Ed). Handbook of labor economics, 1986. v. 2.

DoERINGer, Peter B.; PIORE, Michael J. Internal labor markets and manpower analysis. Lexington, MA: D.C. Heath and Company, 1971.

EhrenberG, Ronald G.; Schwarz, Joshua L. Public sector labor markets. In: Ashenfelter, O.; LAYARD, R. (Ed.) Handbook of labor economics, 1986. v. 2.

FERnANDEs, Reynaldo. Desigualdade salarial: aspectos teóricos. São Paulo: Universidade de São Paulo, 2000. Mimeografado.

Fogel, Walter; LewIn, David. Wage determination in the public sector. In: Industrial and Labor Relations Review, abril, 1974.

FrEEMAN, Richard B. How much has de-unionization contributed to the rise in male earnings inequality? In: Danziger , S.; GotTschalk, P. (Ed.), 1993.

GILL, Indermit et al. Brazil: sustaining the real plan through sustainable public employment reforms. 1997. Mimeografado.

GrEGORY, Robert G; Borland, Jeff. Recent developments in public sector labor markets. In: Ashenfelter, O.; LAYARD, R. (Ed.) Handbook of labor economics. Elsevier Science Publishers, 1999. v. 3.

Gujarati, Damodar N. Basic econometrics. 3. ed. McGraw-Hill, Inc., 1995.

Hewitt, Daniel; RuJCKeghem, Caroline Van. Wage expenditures of central governments, In: IMF Working Paper, 95/11. 1995.

Horn, Murray J. The political economy of public administration. Cambridge: Cambridge University Press, 1995.

IBGE. Contas regionais do Brasil 1985-1997. Rio de Janeiro: IBGE, 1999.

IBGE. Regionalização das transações do setor público: atividade de Administração Pública - 1991-1997. Rio de Janeiro: IBGE, 2000.

Katz, Lawrence F.; Krueger, Alan. Changes in the structure of wages in the public and private sectors. In: Research in Labor Economics, v. 12, 1991. 
Katz, Lawrence F.; Autor, David H. Changes in the wage structure and earnings inequality.

In: Ashenfelter, O.; Layard, R. (Ed.) Handbook of labor economics. Elsevier Science Publishers, 1999. v. 3.

KraAy, Aart; RiJckeghem, Caroline Van. Employment and wages in the public sector: a cross-country study. In: IMF Working Paper, 95/70, 1995.

LAFFONT, Jean-Jacques. Incentives and political economy. Oxford: University Press, 2000.

LindBeCK, Assar; SnOwer, Dennis J. Efficiency wages versus insiders and outsiders. In: European Economic Review, v. 31, 1987.

MACEDO, Roberto. Os salários nas empresas estatais. São Paulo: Editora Nobel, 1985.

MARConi, Nelson. Uma breve comparação entre os mercados de trabalho do setor público e privado. In: Revista do Serviço Público, 48 (1), Brasília, ENAP, 1997.

Mincer, Jacob; PolacheK, Solomon. Family investments in human capital: earnings of women. In: Journal of Political Economy, v. 82, 1974. Suplemento.

Persson, Torsten; Tabellini, Guido. Political economics. Cambridge, MA: MIT Press, 2000.

REDER, Melvin. The theory of employment and wages in non-profit industry, In: Working Paper, n. 42 A, Industrial Relations Section, Princeton University, 1973.

TIROLE, Jean. The internal organization of government. In: Oxford Economic Papers, 46 (1), 1994.

Urani, André; Ramalho, Mariana. A Administração Pública como empregadora: uma avaliação da década de 80. In: Série Seminários n. 5/95, Rio de Janeiro, IPEA, 1995.

VAn Der GaAG; ViJverberg, Win. A switching regression model for wage determinants in the public and private sectors of a developing country. In: Review of Economics and Statistics, 70 (2), 1988.

WiLLIS, Robert J. Wage determinants: a survey and reinterpretation of human capital earnings functions. In: AsHENFELTER, O.; LAYARD, R. (Ed.) Handbook of labor economics. Elsevier Science Publishers, 1986. v. 1. 


\section{Distribuição da força de trabalho segundo as categorias de ocupação}

Participação das diversas categorias de ocupação na força de trabalho - servidores federais estatutários (em \%)

\begin{tabular}{l|r|r|c}
\hline & $\mathbf{1 9 9 3}$ & $\mathbf{1 9 9 6}$ & $\mathbf{1 9 9 9}$ \\
\hline Assistente administrativo & 12,1 & 10,5 & 12,1 \\
\hline Chefe/diretor/assessor & 6,9 & 6,1 & 7,1 \\
\hline Ajudante/auxiliar & 6,5 & 7,3 & 7,8 \\
\hline Professor de ensino superior & 5,5 & 4,9 & 5,0 \\
\hline Servidor público & 4,9 & 6,1 & 4,3 \\
\hline Atendente de enfermagem & 4,5 & 4,7 & 5,0 \\
\hline Agente de saúde pública & 3,2 & 2,2 & 2,0 \\
\hline Médico & 2,7 & 3,2 & 2,1 \\
\hline Motorista & 2,5 & 1,8 & 1,8 \\
\hline Serventuário e técnico da justiça & 2,2 & 2,0 & 4,3 \\
\hline Auditor/contador/analista contábil & 2,1 & 0,7 & 1,9 \\
\hline Fiscal de tributos & 2,1 & 2,3 & 2,4 \\
\hline Porteiro & 2,0 & 1,2 & 1,6 \\
\hline Secretária & 1,8 & 2,0 & 1,8 \\
\hline Vigia & 1,5 & 0,7 & 1,3 \\
\hline Analista econ./financ./orçam./custos & 1,5 & 0,5 & 0,6 \\
\hline Carteiro & 1,3 & 1,5 & 1,3 \\
\hline Operador de computador & 1,2 & 1,6 & 1,0 \\
\hline Faxineiro/servente/zelador & 1,2 & 0,8 & 0,7 \\
\hline Agente da polícia federal & 1,2 & 0,8 & 1,1 \\
\hline Funcionário do IBGE (exclusive recenseador) & 1,1 & 1,1 & 1,3 \\
\hline Encarregado de seção, chefe de área & 1,0 & 0,8 & 0,9 \\
\hline administrativa e industrial, assist. contabilidade & 1,0 & 1,8 & 2,3 \\
\hline Caixa/tesoureiro & 1,0 & 1,0 & 0,5 \\
\hline Datilógrafo & 0,0 & 1,4 & 1,2 \\
\hline Engenheiro & 0,9 & 1,0 & 1,5 \\
\hline Advogado/assist. jurídico & & & continua.. \\
\hline Chefe/diretor/assessor empresas de seguros, & & \\
\hline financeiras e imobiliárias & & & \\
\hline Enfermeiro & 1,2 & 1,2 \\
\hline & & & \\
\hline
\end{tabular}


...continuação

Oficial de justiça

Professor de segundo grau

Analista de laboratório

Técnico de laboratório/químico

Policial rodoviário

Recepcionista/atend. clínica e laboratório

Assistente social

Subtotal deste grupo

Demais categorias

\begin{tabular}{r|r|r}
0,9 & 0,4 & 0,8 \\
\hline 0,7 & 1,1 & 1,5 \\
\hline 0,7 & 0,6 & 1,0 \\
\hline 0,7 & 1,3 & 0,4 \\
\hline 0,6 & 1,2 & 1,0 \\
\hline 0,5 & 1,4 & 1,3 \\
\hline 0,4 & 0,3 & 0,9 \\
\hline 79,3 & 77,1 & 82,0 \\
\hline 20,7 & 22,9 & 18,0 \\
\hline
\end{tabular}

Fonte: PNAD/IBGE.

Inclui os empregados entre 18 e 65 anos de idade.

Participação das diversas categorias de ocupação na força de trabalho - Servidores federais celetistas (em \%)

\begin{tabular}{|c|c|c|c|}
\hline & 1993 & 1996 & 1999 \\
\hline Ajudante/auxiliar & 12,3 & 8,6 & 9,5 \\
\hline Servidor público & 10,4 & 8,8 & 12,4 \\
\hline Caixa/tesoureiro & 6,4 & 8,1 & 6,2 \\
\hline $\begin{array}{l}\text { Encarregado de seção, chefe de área } \\
\text { administrativa e industrial, assist. contabilidade }\end{array}$ & 4,4 & 1,7 & 1,7 \\
\hline Assistente administrativo & 4,0 & 3,6 & 3,8 \\
\hline $\begin{array}{l}\text { Chefe/diretor/assessor empresas de seguros, } \\
\text { financeiras e imobiliárias }\end{array}$ & 3,9 & 3,7 & 3,2 \\
\hline Atendente de enfermagem & 3,2 & 2,8 & 3,5 \\
\hline Operador de computador & 2,5 & 2,2 & 1,7 \\
\hline Engenheiro & 2,4 & 1,3 & 1,9 \\
\hline Carteiro & 2,3 & 3,6 & 3,1 \\
\hline Secretária & 2,2 & 1,0 & 1,4 \\
\hline Funcionário de serviço posta & 1,8 & 1,3 & 1,6 \\
\hline Faxineiro/servente/zelador & 1,8 & 2,2 & 1,9 \\
\hline Chefe/diretor/assessor & 1,6 & 2,1 & 3,3 \\
\hline Médico & 1,3 & 1,8 & 2,4 \\
\hline Analista de sistemas & 1,3 & 1,4 & 2,1 \\
\hline $\begin{array}{l}\text { Técnico de água, energia, esgoto e } \\
\text { telecomunicações }\end{array}$ & 1,3 & 0,9 & 0,0 \\
\hline Motorista & 1,3 & 1,3 & 1,3 \\
\hline Professor de ensino superior & 1,2 & 1,6 & 1,3 \\
\hline Mecânico industrial/de manutenção & 1,1 & 0,6 & 0,3 \\
\hline Técnico em administração/analista de O \& M & 1,1 & 0,2 & 0,3 \\
\hline Eletricista & 1,1 & 1,4 & 0,4 \\
\hline Condutor de trem/metrô & 1,0 & 0,4 & 0,2 \\
\hline Auxiliar de contabilidade & 0,8 & 1,0 & 0,4 \\
\hline
\end{tabular}


...continuação

\begin{tabular}{l|c|c|c}
\hline Agente de saúde pública & 0,8 & 1,5 & 1,0 \\
\hline Recepcionista/atend. clínica e laboratório & 0,7 & 0,7 & 1,0 \\
\hline Telefonista & 0,7 & 1,0 & 0,7 \\
\hline Vigia & 0,7 & 1,1 & 0,6 \\
\hline Funcionários do IBGE (exclusive recenseador) & 0,6 & 1,2 & 0,7 \\
\hline Ajudante operacional & 0,4 & 0,0 & 9,1 \\
\hline Recenseador & 0,1 & 7,6 & 0,2 \\
\hline Subtotal deste grupo & 74,7 & 74,7 & 77,2 \\
\hline Demais categorias & 25,3 & 25,3 & 22,8 \\
\hline
\end{tabular}

Fonte: PNAD/IBGE.

Inclui os empregados entre 18 e 65 anos de idade.

Participação das diversas categorias de ocupação na força de trabalho - Servidores estaduais (em \%)

\begin{tabular}{|c|c|c|c|}
\hline & 1993 & 1996 & 1999 \\
\hline Professor de $1^{\mathrm{a}}$ a $4^{\mathrm{a}}$ série & 10,1 & 9,1 & 8,6 \\
\hline Policial militar & 9,4 & 10,1 & 10,6 \\
\hline Ajudante/auxiliar & 6,5 & 5,1 & 5,1 \\
\hline Faxineiro/servente/zelador & 5,8 & 4,5 & 4,7 \\
\hline Professor de $5^{\mathrm{a}}$ a $8^{\mathrm{a}}$ série & 5,7 & 6,0 & 7,3 \\
\hline Assistente administrativo & 4,7 & 4,4 & 3,9 \\
\hline Professor de $2^{\circ}$ grau & 4,2 & 5,1 & 6,3 \\
\hline Chefe/diretor & 3,7 & 4,2 & 4,7 \\
\hline Servidor público & 3,4 & 4,3 & 4,0 \\
\hline Atendente de enfermagem & 3,0 & 3,8 & 3,9 \\
\hline Secretária & 2,1 & 2,1 & 1,8 \\
\hline Motorista & 1,8 & 1,4 & 1,3 \\
\hline Policial civil & 1,7 & 1,9 & 2,0 \\
\hline Cozinheiro & 1,4 & 1,6 & 1,4 \\
\hline Caixa/tesoureiro & 1,3 & 1,2 & 0,8 \\
\hline Orientador/supervisor pedagógico & 1,2 & 1,5 & 1,7 \\
\hline Vigia & 1,1 & 1,1 & 1,1 \\
\hline Médico & 1,1 & 1,4 & 1,4 \\
\hline Escrivão/escrevente & 1,1 & 1,1 & 1,3 \\
\hline Professor de $1^{\circ}$ grau & 1,0 & 1,2 & 1,0 \\
\hline Bombeiro & 0,9 & 1,1 & 1,4 \\
\hline Recepcionista/atend. de clínica e laboratório & 0,7 & 1,1 & 1,3 \\
\hline Subtotal deste grupo & 71,9 & 73,3 & 75,6 \\
\hline Demais categorias & 28,1 & 26,7 & 24,4 \\
\hline
\end{tabular}

Fonte: PNAD/IBGE.

Inclui os empregados entre 18 e 65 anos de idade. 
Participação das diversas categorias de ocupação na força de trabalho - Servidores municipais (em \%)

\begin{tabular}{|c|c|c|c|}
\hline & 1993 & 1996 & 1999 \\
\hline Professor de $1^{\mathrm{a}}$ a $4^{\mathrm{a}}$ série & 10,8 & 9,6 & 11,8 \\
\hline Faxineiro/servente/zelador & 9,0 & 9,1 & 8,1 \\
\hline Ajudante/auxiliar & 6,3 & 5,2 & 5,4 \\
\hline Lixeiro & 5,8 & 4,3 & 3,4 \\
\hline Chefe/diretor/assessor & 5,2 & 5,5 & 6,5 \\
\hline Vigia & 4,4 & 4,7 & 4,0 \\
\hline Motorista & 4,3 & 4,2 & 3,8 \\
\hline Atendente de enfermagem & 4,0 & 4,2 & 5,4 \\
\hline Servidor público & 3,7 & 5,4 & 4,7 \\
\hline Cozinheiro & 3,7 & 4,2 & 3,8 \\
\hline Assistente administrativo & 2,9 & 2,8 & 3,2 \\
\hline Professor de $5^{\mathrm{a}}$ a $8^{\mathrm{a}}$ série & 2,2 & 3,2 & 3,4 \\
\hline Professor de pré-escola & 2,0 & 2,2 & 1,8 \\
\hline Pedreiro & 1,9 & 1,3 & 0,9 \\
\hline Secretária & 1,8 & 1,9 & 1,6 \\
\hline Ajudante operacional & 1,6 & 0,7 & 1,2 \\
\hline Babá/recreacionista infantil & 1,5 & 1,8 & 1,5 \\
\hline Orientador/supervisor pedagógico & 1,4 & 1,1 & 1,4 \\
\hline Jardineiro & 1,2 & 0,6 & 0,8 \\
\hline Operador máquinas const. civil & 1,1 & 0,9 & 0,9 \\
\hline Fiscal (não de tributos) & 1,1 & 0,8 & 0,8 \\
\hline Professor de $2^{\circ}$ grau & 1,0 & 1,6 & 1,0 \\
\hline Professor de $1^{\circ}$ grau & 0,9 & 1,0 & 0,9 \\
\hline Prefeito/vereador/secretário & 0,9 & 1,1 & 1,2 \\
\hline Recepcionista/atend. de clínica e laboratório & 0,9 & 1,6 & 2,1 \\
\hline Médico & 0,8 & 1,4 & 1,0 \\
\hline Telefonista & 0,7 & 1,0 & 0,4 \\
\hline Agente de saúde pública & 0,3 & 0,9 & 2,3 \\
\hline Subtotal deste grupo & 81,4 & 82,3 & 83,3 \\
\hline Demais categorias & 18,6 & 17,7 & 16,7 \\
\hline
\end{tabular}

Fonte: PNAD/IBGE.

Inclui os empregados entre 18 e 65 anos de idade. 
Participação das diversas categorias de ocupação na força de trabalho - Setor privado (em \%)

\begin{tabular}{|c|c|c|c|}
\hline & 1993 & 1996 & 1999 \\
\hline Comerciante & 8,8 & 10,0 & 9,8 \\
\hline Motorista & 5,4 & 5,5 & 5,3 \\
\hline Ajudante/auxiliar & 5,1 & 4,6 & 4,4 \\
\hline Faxineiro/servente/zelador & 3,7 & 3,6 & 3,5 \\
\hline Ajudante/servente de obras & 3,6 & 3,3 & 3,7 \\
\hline Diversos - atividades operacionais simples & 3,4 & 4,1 & 4,4 \\
\hline $\begin{array}{l}\text { Encarregado de seção, chefe de área } \\
\text { administrativa e industrial, assist. contabilidade }\end{array}$ & 2,6 & 2,4 & 2,0 \\
\hline Ajudante operacional & 2,6 & 2,4 & 2,6 \\
\hline Pedreiro & 2,5 & 2,4 & 1,9 \\
\hline Vigia & 2,2 & 2,1 & 1,8 \\
\hline Alfaiate/costureiro & 2,0 & 1,8 & 1,9 \\
\hline Cozinheiro & 1,8 & 2,0 & 1,9 \\
\hline Mecânico de meios de transporte & 1,8 & 1,7 & 1,6 \\
\hline Secretária & 1,7 & 1,5 & 1,3 \\
\hline Gerente/diretor no comércio & 1,7 & 1,8 & 1,8 \\
\hline Recepcionista/atend. de clínica e laboratório & 1,4 & 2,2 & 2,7 \\
\hline Operário na indústria de calçados & 1,4 & 1,1 & 1,0 \\
\hline Operário/auxiliar/pintor de áreas diversas & 1,3 & 1,2 & 1,2 \\
\hline Caixa & 1,3 & 1,5 & 1,5 \\
\hline $\begin{array}{l}\text { Balconista/ajudante/copeiro de bares e } \\
\text { lanchonetes }\end{array}$ & 1,2 & 1,2 & 1,2 \\
\hline Marceneiro & 1,2 & 1,0 & 1,0 \\
\hline Segurança & 1,1 & 1,2 & 1,3 \\
\hline Mecânico industrial/de manutenção & 1,1 & 1,1 & 0,9 \\
\hline Vendedor & 1,1 & 1,1 & 1,2 \\
\hline Atendente de enfermagem & 1,0 & 1,0 & 1,1 \\
\hline $\begin{array}{l}\text { Empacotador/etiquetador/engarrafador/ } \\
\text { embalador }\end{array}$ & 1,0 & 0,9 & 1,0 \\
\hline $\begin{array}{l}\text { Diretor/gerente na ind. transformação/ } \\
\text { gerente industrial/financeiro }\end{array}$ & 1,0 & 0,9 & 0,9 \\
\hline Operador de computador & 1,0 & 0,8 & 0,7 \\
\hline Garçom & 0,9 & 1,0 & 1,0 \\
\hline Porteiro & 0,7 & 1,0 & 1,0 \\
\hline Auxiliar de contabilidade & 0,8 & 1,0 & 0,9 \\
\hline Subtotal deste grupo & 66,4 & 67,4 & 66,5 \\
\hline Demais categorias & 33,6 & 32,6 & 33,5 \\
\hline
\end{tabular}

Fonte: PNAD/IBGE.

Inclui os empregados entre 18 e 65 anos de idade. 


\section{A evolução do perfil da força de trabalho e das remunerações nos setores público e privado ao longo da década de 1990}

\section{Nelson Marconi}

Este artigo buscará traçar um panorama da evolução do perfil da força de trabalho e dos salários praticados no setor público ao longo da década de 1990, buscando compará-la com o comportamento observado no setor privado, e sugerir medidas para a melhoria do sistema salarial. Na primeira seção, será apresentada uma comparação entre os perfis da força de trabalho nos dois setores, enquanto na segunda será analisada a evolução das remunerações e desenvolvido um modelo geral de determinação dos salários, que possibilitará a análise dos diferenciais de remuneração entre os trabalhadores com características pessoais semelhantes nos dois setores. A terceira seção se ocupará da discussão em torno das distorções que ainda persistem no sistema salarial no setor público federal, apesar do processo de aprimoramento pelo qual passou nos últimos anos, e apresentará algumas sugestões para suprimi-las.

\section{La evolución del perfil de la fuerza de trabajo y de la remuneración en los sectores públicos y privados a lo largo de la década de 1990}

\section{Nelson Marconi}

Este artículo buscará trazar un panorama de la evolución del perfil de la fuerza de trabajo y de los salarios practicados en el sector público a lo largo de la década de 1990, buscando compararla con el comportamiento observado en el sector privado, y sugerir medidas para la mejoría del sistema salarial. En la primera sección, será presentada una comparación entre los perfiles de la fuerza de trabajo en los dos sectores, mientras en la segunda será analizada la evolución de las remuneraciones y desarrollado un modelo general de determinación de los salarios que posibilitará el análisis de los diferenciales de salario entre los trabajadores con características personales semejantes en los dos sectores. La tercera sección se ocupará de la discusión en torno de las distorsiones que aún persisten en el sistema salarial en el sector público federal, a pesar del proceso de esmero por el cual pasó en los últimos años, y presenta algunas sugerencias para suprimirlas.

\section{The evolution of workforce profile and remuneration in public and private sectors along the 1990s \\ Nelson Marconi}

This article will present an overview of the evolution of the work force profile and of the wages practiced in the public sector along the 1990s, seeking to compare it with the behavior observed in the private sector and to suggest measures for the improvement of the wage structure. In the first section, it will be introduced a comparison between the work force profiles in the two sectors, while in the second section it will be analyzed the evolution of the wages and it will be developed a general model of determination of the wages, which will enable the analysis of the wage differential between workers with similar personal characteristics in the two sectors. The third section will include a discussion about the distortions that still persist in the wage system in the federal government, besides its improvement in the last years, and it will introduce some suggestions to suppress them.
Revista do

Serviço

Público

Ano 54

Número 1

Jan-Mar 2003

Nelson Marconi

é doutor em

Economia pela

Fundação

Getúlio Vargas/

SP, professor

doutor de

Economia da

Pontifícia

Universidade

Católica/SP e

ex-diretor de

Carreiras e

Remuneração

do Ministério da

Administração

Federal e

Reforma do

Estado.

Contato: nmarconi@ uol.com.br 